\title{
Effect of consumer's decisions on acrylamide exposure during the preparation of French fries. part I: Frying conditions
}

\author{
Marta Mesias, Cristina Delgado-Andrade, Francisca Holgado, Lucía González-Mulero, \\ Francisco J. Morales
}

Instituto de Ciencia y Tecnología de Alimentos y Nutrición (ICTAN-CSIC), C/José Antonio Novais, I0, E28040 Madrid, Spain

\begin{abstract}
Variability in home-cooking practices affects dietary exposure to acrylamide, limiting risk evaluation. Two observational tests (controlled and randomized) involving 127 volunteers was designed to investigate the influence of consumer decisions on acrylamide formation during the preparation of French fries. Consumer practices were recorded during pre-frying, frying and post-frying stages. Reducing sugar content, asparagine, moisture, acrylamide, moisture, weight loss and color were evaluated. In the controlled assay, mean acrylamide content was $508 \mu \mathrm{g} / \mathrm{kg}$ and volunteers took a mean frying time of $91.9 \mathrm{~s} \mathrm{(87.5-96.4,} \mathrm{C.I.} \mathrm{95 \% ).} \mathrm{The} \mathrm{narrow}$ confidence interval of $8.9 \mathrm{~s}$ represented an increase of $120 \mu \mathrm{g} / \mathrm{kg}$ in the acrylamide content of the fried potato. Average acrylamide content in the randomized assay $(215 \mu \mathrm{g} / \mathrm{kg}, 150-280 \mu \mathrm{g} / \mathrm{kg}, \mathrm{C} . \mathrm{l} .95 \%)$ was significantly lower than in the controlled assay. Amongst the culinary practices applied for the potato variety evaluated, washing of the potato strips significantly reduced acrylamide content in French fries. The percentage of samples with acrylamide lower than the benchmark value $(500 \mu \mathrm{g} / \mathrm{kg})$ was $54 \%$ and $93 \%$ for the controlled and randomized assays, respectively. Estimated average dietary exposure to acrylamide from French fries in adults was $5.65 \mu \mathrm{g} /$ day, which corresponds to a margin of exposure of 2105 for carcinogenicity.
\end{abstract}

\section{INTRODUCTION}

Acrylamide is a chemical process contaminant classified by the International Agency for Research on Cancer as a probable carcinogen for humans (IARC, 1994). The Joint Food and Agriculture Organization/World Health Organization Expert Committee on Food Additives consider acrylamide to be a human health concern (JECFA, 20II). The Center for Food Safety and Applied Nutrition (CFSAN) from the U.S. Food and Drug Administration (FDA) monitors its levels in foods because of its potential to affect human health and as consequence guidelines to reduce exposure from foods was launch in 2016 (FDA, 2016). Nowadays, FDA is not suggesting maximum recommended levels for acrylamide. The European Commission has recently established relevant mitigation measures and benchmark levels (EC, 2017). Acrylamide is formed in a wide range of thermally treated foods, mainly through the Maillard reaction at temperatures higher than $120^{\circ} \mathrm{C}$ and at low moisture conditions (Lineback et al., 2012). The main acrylamide precursors in foods are asparagine and compounds containing $\alpha$-hydroxycarbonyl groups (i.e. reducing sugars) (Stadler et al., 2002; Friedman, 20I5), although molecules with $\alpha, \beta, \gamma, \delta$-diunsaturated carbonyl groups or $\alpha$-dicarbonyl groups can also participate in the reaction (Zamora and Hidalgo, 2008; Yuan et al., 2008). Coffee, cereal based products and, particularly, potato-fried products are the main contributors to the dietary intake of acrylamide (EFSA, 20I5; Abt et al., 2019). Its high occurrence in potato-fried products is due to both the high content of reducing sugars and asparagine in the fresh tuber, and the intensity of the thermal treatment applied during frying (Matthäus et al., 2004). 
Since the confirmation of the presence of acrylamide in foods, several initiatives focused on the mitigation of its formation in potato-based products have been launched and periodically updated (Medeiros et al., 20 I I; Powers et al., 2017). There are several guidelines, with specific recommendations for acrylamide mitigation in potato-based products produced in the food sector. Examples include, the report from the FDA (FDA, 20I6), the acrylamide toolbox compiled by the FoodDrinkEurope (FDE, 2019), the code of practice adopted from FAO/WHO Codex Alimentarius (Codex Alimentarius, 2009), and the EU Regulation 2017/2I58 (EC, 20I7). This Regulation established a benchmark level of $500 \mu \mathrm{g} / \mathrm{kg}$ for French fries (EC, 2017). Nowadays, most of the mitigation strategies are targeted towards the industrial sector, ensuring the application of well-controlled, supervised and standardized processing protocols. However, cooking practices in private settings are not efficiently supervised, increasing uncertainty in relation to this process. The influence of the lack of a standardized protocol was investigated in food service establishments and the training of food handlers was identified as the most effective strategy for reducing acrylamide formation (Sanny et al., 20I2). This is a key issue since preferences in home-cooking have a substantial impact on human dietary acrylamide exposure, increasing the presence of the contaminant by up to $80 \%$, depending on domestic habits and the conditions for potato frying (EFSA, 20I5). Recently, our research group has reported acrylamide levels ranging between 24 and $4200 \mu g / k g$ in French fries prepared in two-hundred and eight Spanish households, taking into account the seasonality of the fresh tuber (Mesias et al., 2018; 2020). The wide variability found in acrylamide content in the domestic setting reinforces the importance of considering culinary practices in order to make reliable estimations of dietary acrylamide exposure.

The contribution of the domestic cooking practices to acrylamide exposure is currently a sticking point in risk evaluations of this contaminant. Observational investigations evaluating the influence of consumer habits on acrylamide exposure in the domestic setting are scarce and food safety agencies aim to further results in this area. It is important to mention the report from the U.K. Food Standards Agency that estimated levels of acrylamide intake from potato-based foods, considering consumer behavior by recording in-home responses via observational research (FSA, 20I4). This investigation concluded that visual assessment was usually more influential for participants during food preparation than abiding by intended timings for frying. Consumers have their own systems for finding the proper combination of temperature and time and, consequently, practices in a domestic setting vary greatly. This statement has been recently corroborated in an observational study in Spanish households (Mesias et al., 2020). Previous investigations into food service establishments also identified variability due to a lack of standardized control of frying temperatures and frying times as a result of inadequate frying equipment (Sanny et al., 20 I2). Indeed, acrylamide content was significantly reduced in French fries when food handlers properly followed the frying instructions provided by the food service establishment (Sanny et al., 2013). Although commercial fryers provide user manuals containing tips for proper and healthy frying of a wide variety of foods, it is ultimately the consumer who will choose the pre-frying operations (if any), temperature conditions and frying end-point. This is normally chosen according to subjective criteria, with color appearance being a key aspect. Thus, the different decisions made by consumers regarding French fry preparation will affect acrylamide formation. Regarding pre-frying operations, Mesias, Delgado-Andrade, and Morales (2019a) described the reducing effect of simple mitigation strategies (soaking in water at different times/temperatures, adding weak $\mathrm{pH}$ modifiers or salt) on the formation of this contaminant in different vegetable snack formulations.

Considering all of these consumer-dependent factors, a double observational scenario was designed to investigate the influence of consumer practices on acrylamide formation during the preparation of French fries. The first scenario was a controlled assay that kept most variables fixed, apart from consumer decisions regarding the frying endpoint. The second scenario was a randomized trial in which participants proceeded 
without restrictions on handling or frying practices. The only controlled aspects were the use of the same raw material (in-season potato tuber) and type of cooking appliance (atmospheric deep-fryer). Results are discussed in terms of the established benchmark level for acrylamide in the EU and its implications for exposure.

\section{MATERIALS AND METHODS}

\section{I. Chemicals and reagents}

Potassium hexacyanoferrate (II) trihydrate (98\%, Carrez-I) and zinc acetate dehydrate (>99\%, Carrez-II) were obtained from Sigma (St. Louis, USA). 13C3-labelled acrylamide ( $99 \%$ isotopic purity) was obtained from Cambridge Isotope Laboratories (Andover, MA, USA). Formic acid (98\%), D (+) glucose, D (-) fructose, D () sorbitol, ethanol, methanol (99.5\%) and hexane were obtained from Panreac (Barcelona, Spain). Deionized water was obtained from a Milli-Q Integral 5 water purification system (Millipore, Billerica, MA, USA). All other chemicals, solvents and reagents were of analytical grade.

\subsection{Selection of the reference fresh potato}

Potato tubers (Solanum tuberosum L. cv. Agata, Elodie, Soprano, Agria, Sunita) were bought from a local market. Four batches of stored potato (Agata, Elodie, Soprano, and Agria) and three batches of inseason potato (Soprano, Elodie, Sunita) from two different geographical origins (Spain and France) were acquired. Samples were stored at $14-16^{\circ} \mathrm{C}$ for 2 days after purchase and reconditioned at room temperature before testing. Potato tubers were peeled and cut into pieces to create a standard French potato shape $(0.8 \times 0.8 \times$ $5 \mathrm{~cm}$ ). Strips from at least three tubers from the same batch were mixed. Ten strips were subjected to an ordinary frito-test for French fries in an electric fryer under controlled conditions for $180 \mathrm{~s}$ at $175^{\circ} \mathrm{C}$. A calibrated K-type thermocouple data logger (Delta Ohm, Caselle di Selvazzano, Italy) was used to monitor the temperature of frying oil and regulate the fryer in order to reduce temperature shifts. A set of three domestic deep-fryers with a capacity of $3 \mathrm{~L}$ and with an immersed 2300 w electric heater (Tefal, Model Filtra-Pro-F335, France) was used. Sunflower oil was used as the frying oil. The aptitude of the potato to frying was visually evaluated according to its color and overall appearance by a semitrained panel (data not shown). A representative sample of the batch of in-season potatoes used in the observational assays was freeze-dried for later determination of reducing sugars and asparagine.

\subsection{Volunteers and frying habits questionnaire}

Two cohorts of volunteers were recruited from the Community of Madrid (Spain). Participants were not made aware of the purpose of the research in order to avoid any influence on the results. All participants gave passive consent for collected information to be used and did not receive any incentive for participation. Volunteers filled out a questionnaire which covered sociodemographic data, cooking experiences, consumption frequency of French fries, portion size usually consumed and quality preferences for French fries. Questions were structured according to check boxes with unique or multiple possible answers. The cohort did not explicitly attempt to address differences between sociodemographic groups in terms of cooking practices.

\subsection{Controlled conditions assay}

A cohort of one hundred volunteers participated in the observational assay under controlled frying conditions in the experimental kitchen at the Institute of Food Science, Technology and Nutrition (ICTAN-CSIC, Madrid, Spain). Members of the research team controlled the main variables pertaining to pre-frying (raw material, peeling, cutting), frying (temperature, potato:oil mass ratio) and post-frying (draining oil excess, cooling) stages of French fry preparation (Fig. I). Tubers had been previously selected and were peeled and cut into strips 
$(0.8 \times 0.8 \times 5 \mathrm{~cm})$. A fixed amount $(\sim 45 \mathrm{~g})$ was placed in the fryer basket. Fryers and frying oil were as described above. The initial temperature of the frying oil was set at $175^{\circ} \mathrm{C}$ (probe-controlled). Once the basket with the potato strips was immersed in the frying oil, volunteers were free to check the progression of frying and decide the end-point according to their preferences. Total frying time (expressed as seconds) was recorded by a timer. The controlled assay was conducted in May 2019. Samples were drained to remove excess oil, weighted and cooled, and stored for further analyses.

\subsection{Randomized conditions assay}

A cohort of twenty-seven volunteers not included in the previous trial participated in the observational randomized assay. This assay aimed to evaluate the impact of population culinary habits on the preparation of French fries (Fig. I), including considerations of frying end-point decisions on acrylamide formation. Volunteers were provided with the same batch of fresh potato used for the controlled assay. On this occasion, volunteers received three unhandled tubers, an electric deepfryer with sunflower oil $\left(3 \mathrm{~L}\right.$ ) pre-tempered at $150^{\circ} \mathrm{C}$ (probecontrolled) and all of the facilities at the experimental kitchen at ICTAN-CSIC. They were asked to mimic the frying practices they employ at home. Volunteers freely selected their pre-frying operations (peeling, washing, cut type, soaking, draining, drying, etc.), frying temperature (controlled by the fryer thermostat), amount of potato for frying, frying time, and the frying end-point according to their preferences. Participants prepared French fries following their own home-cooking practices. Meanwhile, researchers observed and recorded all elements of interest for each stage that could influence acrylamide formation. The randomized assay was conducted in May 2019. Once the volunteers decided that samples were ready for consumption, French fries were drained to remove excess oil, weighed, cooled and stored for further analyses. Modifications in the usual frying habits of participants due to the presence of the research team monitoring their practices could not be controlled.

\subsection{Determination of moisture content}

Moisture was determined gravimetrically in a constant weight of fresh and fried potato in an oven heated at $105^{\circ} \mathrm{C}$ for $24 \mathrm{~h}$ according to the AOAC (1999) method.

\subsection{Determination of weight loss after frying}

Before frying, the weight of fresh potato strips in the basket was recorded for each trial. After frying, excess surface oil was gently removed by the research team with absorbent paper and the French fries were weighted. Percentage weight loss was determined as follows: $100-[$ fried potato weight $(\mathrm{g}) \times 100 /$ fresh potato weight (g)].

\subsection{Determination of reducing and total sugars}

Glucose, fructose and sucrose content in fresh potatoes was determined using high performance liquid chromatography with refractive index detector (HPLC-RID). The procedure was a slightly modified version of the method described by Ayvaz (2014). Six hundred $\mathrm{mg}$ of freeze-dried sample were weighed and mixed with $9 \mathrm{~mL}$ of $80 \%(\mathrm{v} / \mathrm{v})$ ethanol and $\mathrm{I} \mathrm{mL}$ of sorbitol $(10 \mathrm{mg} / \mathrm{mL})$ as an internal standard. Following vortex agitation, the mixture was incubated at $50^{\circ} \mathrm{C}$ and $900 \mathrm{rpm}$ for I h, and centrifuged at $4^{\circ} \mathrm{C}$ and $5000 \mathrm{rpm}$ for $20 \mathrm{~min}$. The supernatant was transferred into a new tube and ethanol was evaporated using TurboVap equipment (Biotage, Uppsala, Sweden). The aqueous extract was purified by solid phase extraction with a SCX cartridge (Supelco, Sigma Aldrich, Missouri, USA) and filtered ( $0.22 \mu \mathrm{m}$ pore-size membrane) prior to HPLC analysis. Twenty $\mu \mathrm{L}$ of extract were injected into the HPLC System LC-20 AD with a RID-10 A (Shimadzu, Scientific Instruments, INC, Columbia, MD). Analytical separation was achieved with a Rezex RCMMonosaccharide $\mathrm{Ca}^{2+}$ column $\left(300 \times 7.8 \mathrm{~mm}, 8 \mu \mathrm{m}\right.$; Phenomenex, Torrance, CA, USA) at $80^{\circ} \mathrm{C}$ in isocratic 
elution, with a mobile phase of deionized water at a flow rate of $0.6 \mathrm{~mL} / \mathrm{min}$. Sugars were quantified with standard solutions spiked with sorbitol. Reducing sugar (glucose + fructose) and total sugar (glucose + fructose + sucrose) content were expressed as $\mathrm{g} / \mathrm{kg}$ of sample (fresh matter). Analysis was done in triplicate.

\subsection{Determination of asparagine}

Asparagine content in the fresh tuber was determined in the freeze dried sample by gas chromatographyflame ionization detection (GC-FID), according to Farkas and Toulouee (2003), with some minor modifications as described in Mesias et al. (2018). A GC-FID (Agilent GC 7820 A FID) equipped with an automatic injector and an amino acid dedicated column (Zebron ZBAAA capillary; $10 \times 0.25 \mathrm{~mm}$ ) was used. The starting oven temperature was set at $110^{\circ} \mathrm{C}$ and increased $32^{\circ} \mathrm{C}$ per minute until $320^{\circ} \mathrm{C}$ was reached. An aliquot of the derivatized sample $(\mathrm{I} \mu \mathrm{L})$ was injected in split mode $(15: \mathrm{I})$ at $250^{\circ} \mathrm{C}$. The FID detector was set to $320^{\circ} \mathrm{C}$ and carrier helium gas flow rate was maintained at $1.5 \mathrm{~mL} / \mathrm{min}$ whilst in process. External calibration was carried out using asparagine standard and results were corrected according to norvaline recovery, with this being used as an internal standard. Free asparagine content was expressed as $\mathrm{g} / \mathrm{kg}$ of sample (fresh matter). Analysis was performed in triplicate.

\subsection{Determination of CIElab color}

The color of different areas of fresh and fried potato was measured at room temperature using a HunterLab Spectrophotometer CM-3500D colorimeter (Hunter Associates laboratory, Stamford, Connecticut, USA). E index was calculated according to the following equation: $E=\left(L^{2}+a^{2}+b^{2}\right)^{1 / 2}$. The equipment was calibrated with a standard calibration CR-A43 white plate $(\mathrm{a} * / 0.3156, \mathrm{~b} * / 0.3319, \mathrm{~L} * / 93.80)$.

\subsection{Determination of acrylamide}

Acrylamide in fried potato was determined via liquid chromatography-electrospray ionization-tandem mass spectrometry (LC-ESI-MS/MS) as described by Mesias and Morales (2015). The recovery rate of acrylamide spiked to the samples was between 90 and 106\%. Relative standard deviations (RSD) for the precision, repeatability and reproducibility of the analysis was calculated as $2.8 \%, 1.2 \%$ and $2.5 \%$, respectively. The limit of the quantitation was set at $20 \mu \mathrm{g} / \mathrm{kg}$. The accuracy of results has recently been demonstrated in potato crisps and French fries through four proficiency tests launched by the Food Analysis Performance Assessment Scheme (FAPAS) program. This analysis yielded z-scores of 0.2 (Test 3065, May-June 2016), - 0.2 (Test 307I, Feb-March 2017), 0.0 (Test 3085, Sep-2018) and 0.3 (Test 3089, Feb-2019). Results of acrylamide were expressed as $\mu \mathrm{g} / \mathrm{kg}$ of sample (fresh matter). Analysis was done in triplicate.

\subsection{Determination of polar compounds in oil}

Total polar compounds were measured in the frying oil by a handheld Testo 270 device (Testo INC, New Jersey, USA) which provides a rapid method based on the dielectric constant of oil. Results were expressed as percentage of total polar material $(\mathrm{g} / 100 \mathrm{~g}$ oil). The content of total polar compounds in the frying oil after every trial was evaluated and found to always be below $8.5 \%$.

\subsection{Dietary exposure assessment}

Daily acrylamide intake from French fries was estimated by combining data for French fry consumption frequency reported by volunteers, typically consumed portion size and acrylamide content of the French fries prepared by each volunteer. An average body weight (bw) of $70 \mathrm{~kg}$ was used to estimate daily exposure to acrylamide from French fries, expressed as $\mu \mathrm{g} / \mathrm{kg}$ bw/day. The margin of exposure (MOE) approach was applied to carry out risk assessment for acrylamide provided by French fries. MOE was calculated as a $B M D L_{10}$ value (Benchmark Dose Lower Confidence Limit), divided by respective total acrylamide exposure. This assumed 
$430 \mu \mathrm{g} / \mathrm{kg}$ bw/day as the $\mathrm{BMDL}_{10}$ value for neurotoxicity (peripheral nerve axonal degeneration in male rats) and $170 \mu \mathrm{g} / \mathrm{kg}$ bw/day for carcinogenicity (Harderian gland adenocarcinomas in mice) as described by EFSA (20I5).

\subsection{Statistical analysis}

Statistical analyses were performed using SPSS version 23.0 (SPSS Inc., Chicago, IL). Student's t-test followed by the Fisher's test were used to identify the overall significance of differences between variables. The homogeneity of variances was determined with Levene's test and the Shapiro-Wilk W test was applied to check for normality. Relationships between the different variables were evaluated by computing Pearson's and Spearman's linear correlation coefficients for parametric or nonparametric variables, respectively. All statistical parameters were evaluated at $\mathrm{p}<0.05$.

\section{RESULTS AND DISCUSSION}

\section{I. Description of participants and consumption habits}

One-hundred twenty-seven participants completed the observational frying assays $(n=100$ for controlled assay; $n=27$ for randomized assay). Participants filled in a questionnaire including sociodemographic information and French fry consumption habits for each assay and the combined dataset (Table I). The general profile participants was female (71.7\%), with medium-high experience in cooking (81.9\%). The age of participants was equally distributed and ranged from 18 to 65 years old, except for one participant who was older than 65 years old. The gender and age distribution of participants were similar to that described previously by Mesias et al. (2018) and Mesias et al. (2020) for observational studies of home-cooking practices in Spanish homes. One-third of the combined cohort of participants reported consuming French fries weekly (28.3\%) or monthly (39.4\%). A low proportion of participants $(5.5 \%)$ declared never consuming French fries. Concerning portion size, most volunteers (79.6\%) usually consumed $40-70 \mathrm{~g}$ portions French fries.

\subsection{Characterization of fresh potato}

A preliminary frito-test was carried out with seven different batches of fresh potatoes in order to identify the most appropriate reference potato for the frying assays. Most of the tested potato batches darkened very rapidly, whilst remaining undercooked inside, when using reference frying conditions. Darkening was more evident for batches of stored potatoes. This unwanted effect showing that the inadequacy of the culinary aptitude for potato frying is related to the higher reducing sugar content seen in stored potatoes when compared with in-season potatoes (Rosen et al., 2018). In contrast, the batch of the Sunita potato variety took excessive time (>300 s) to reach the desirable golden color and was also dismissed. Thus, the early season potato variety Elodie was selected for use in the observational studies with volunteers. When exposed to frying, the batch of the Elodie variety darkened at a moderate rate, whilst maintaining an adequate texture and overall appearance over time (data not shown). Visual assessments of color and texture by consumers predominantly decide the end of frying (FSA, 2014; Mesias, Delgado-Andrade, Holgado, Morales, 2019b). The agronomical and culinary characteristics, as well as the analytical parameters for the reference fresh potato are evaluated (Supplementary Table I). Moisture (80.9\%), asparagine $(3.4 \mathrm{l} \mathrm{g} / \mathrm{kg})$, reducing sugar $(5.2 \mathrm{lg} / \mathrm{kg}$ ) and total sugar $(12.68 \mathrm{~g} / \mathrm{kg})$ content in fresh potato were found to be in the same order of magnitude as in previous results reported by our research group (Mesias et al., 2018, 2019b) and other researchers (De Wilde et al., 2006; Halford et al., 2012; Muttucumaru et al., 2017; Rosen et al., 2018). Vivanti et al. (2006) reported the levels (average; min-max) of the moisture (79.8\%; 75.0-85.3), free asparagine (2.26 g/kg; 0.15-10.64), glucose (3.32 g/kg; 0.15-24.08), fructose (2.01 g/kg; 0-6.01) and total sugar ( $8.21 \mathrm{~g} / \mathrm{kg} ; 1.07-34.57)$ content in 31 varieties of fresh potato sold at retail in Italy and US. Similarly, Mesias et al. (2020) reported the levels (average; min-max) of moisture (80.1\%; 66.9-84.9), free asparagine $(2.47 \mathrm{~g} / \mathrm{kg} ; 0.45-6.63)$ and reducing sugar 
$(8.56 \mathrm{~g} / \mathrm{kg} ;<3.0-33.98)$ content in fresh potato varieties used in 208 Spanish households for domestic preparation of French fries. Similarly, Storey (2007) reported ranges from 72 to $85 \%$ for moisture, $0.1-6.0$ $\mathrm{g} / \mathrm{kg}$ for glucose, $0.1-6.0 \mathrm{~g} / \mathrm{kg}$ for fructose, $1.3-6.8 \mathrm{~g} / \mathrm{kg}$ for sucrose, and $1.1-5.3 \mathrm{~g} / \mathrm{kg}$ for free asparagine in fresh tuber.

\subsection{Controlled assay}

In the controlled assay, most of the cooking practices used for the preparation of French fries at the prefrying, frying and post-frying stages were previously fixed by the research team (Table 2). Volunteers only freely decided the frying end-point according to their preferences regarding how the finished product should look. All volunteers declared that visual color appearance was the major criteria for stopping frying. The research team peeled the tubers, removed their imperfections and cut them into equally sized strips (Fig. I). Following cutting, tubers and strips were not washed or soaked and, consequently, not drained or dried. In all cases, a similar quantity of strips $(43.4 \pm 2.7 \mathrm{~g})$ was placed in the fryer basket and deep-fried in a fryer containing $3 \mathrm{~L}$ of sunflower oil pre-heated to $175^{\circ} \mathrm{C}$ (Table 3). Consequently, the average potato:oil ratio for the 100 trials was $14.5 \pm 0.9$. Starting temperature was always probe-controlled and set at $175^{\circ} \mathrm{C}$. Mean temperature at the end of the frying was $167.7 \pm 3.4^{\circ} \mathrm{C}$. Participants chose to stop frying noteworthy that the $95 \%$ confidence interval associated with the mean was only $8.9 \mathrm{~s}$. This shows that criteria used to decide frying end-point was largely similar between participants. Two volunteers carried out extremely long frying cycles of 163 and $168 \mathrm{~s}$ and were, therefore, identified as outliers in the data distribution.

The relationship between frying time and acrylamide formation has been extensively reported in laboratory trials under controlled conditions (i.e. Matthäus et al., 2004; Pedreschi et al., 2006; De Wilde et al., 2006; Gökmen et al., 2007). Reported a $55 \%$ increase in going from 160 to $175^{\circ} \mathrm{C}$, and a further increase by a factor of 3.7 in going from 175 to $180^{\circ} \mathrm{C}$. However, the progressive and intensive dehydration of the outer part of the strip as compared to the inside also impact on the rate of formation of acrylamide in French fries. The acrylamide content of the surface of the French fries was 72 , and $2747 \mu \mathrm{g} / \mathrm{kg}$ after frying for $9 \mathrm{~min}$ at 150 , and $170^{\circ} \mathrm{C}$, respectively, while the core was free of acrylamide after frying for $9 \mathrm{~min}$ at 150 and $170^{\circ} \mathrm{C}$ (Gökmen et al., 2006). In our study, once the fryer basket was immersed in oil, oil temperature decreased rapidly from $175^{\circ} \mathrm{C}$ to about $163.5^{\circ} \mathrm{C}$ in $35 \mathrm{~s}$. The temperature increased progressively $\left(\sim 0.12^{\circ} \mathrm{C} / \mathrm{s}\right)$ for the next $130 \mathrm{~s}$ until returning to the reference temperature of $175^{\circ} \mathrm{C}$ after $140 \mathrm{~s}$ from the start (Supplementary Fig. I). Most volunteers (93\%) decided to stop the frying process after between 45 and $130 \mathrm{~s}$, corresponding to the period at which frying oil temperature increases rapidly. At the mean frying end-time recorded when chosen by volunteer's, a temperature of $168.5^{\circ} \mathrm{C}$ is extrapolated from the temperature profile of the model. This is in line with the observed results $\left(167.7 \pm 3.4^{\circ} \mathrm{C}\right.$, Table 3$)$.

As expected, moisture content decreased after frying until it reached a mean content of $71.0 \pm 2.3 \%$ (Table 3). The potato strip suffers extensive dehydration during the full frying process since, once added to the hot oil, the temperature of its surface layers rises rapidly. The core temperature does not exceed $103-104^{\circ} \mathrm{C}$ within 9 min of frying regardless of the frying temperature, whereas the temperatures attained in the surface were much higher (Gökmen et al., 2006). As water starts to boil at $100{ }^{\circ} \mathrm{C}$, this is then released from the surface as bubbles. The high temperature promotes the formation of a crust in the surface layers and as frying proceeds. The thickness of the developed crust increases, decreasing the number of steam bubbles. Crust formation will depend on the thickness of the potato strip, with thick potatoes exhibiting less moisture loss, whilst thin potatoes become almost fully dehydrated (Miranda and Aguilera, 2006; Medeiros, Mestdagh and De Meulenaer, 2012). There is high reproducibility in the moisture content (3.2\% variation coefficient) of the fried potato samples used in the controlled assay, with the moisture content ranging from $66.2 \%$ to $75.2 \%$ 
(data not shown). Similarly, average weight loss was $31.3 \pm 2.7 \%$, also showing a high reproducibility $(8.6 \%$ variation coefficient) concerning to participants' decisions determining the end of frying. This again infers similarity between the criteria used by participants to assess the end of frying. This was not the case for the variability seen in weight loss and moisture content of fried potatoes due to the influence of oil uptake. Briefly, weight loss is the net balance between water evaporation and oil uptake in potato strips (i.e. Romani et al., 2008; Medeiros et al., 2012; Yang et al., 2016). The fat content of the French fries of good culinary quality should varied between 17 and 20.5\% (Fiselier et al., 2006). The color E-value of the fried potato also remained stable, with an average of $60.8 \pm 2.6$ (Table 3). Mean acrylamide content was $508 \pm 302 \mu \mathrm{g} / \mathrm{kg}$, with a wide confidence interval of between 448 and $568 \mu \mathrm{g} / \mathrm{kg}$, and a variation coefficient of $59.3 \%$ (Table 3). Three outliers were identified for the acrylamide distribution, these being I $40 \mathrm{I} \mu \mathrm{g} / \mathrm{kg}, \mathrm{I} 457 \mu \mathrm{g} / \mathrm{kg}$ and I $536 \mu \mathrm{g} / \mathrm{kg}$. Particularly, these samples reported higher weight loss $(>35.2 \%)$, lower moisture content $(<69.1 \%)$ and a darker color $(E$ $<54.5)$ than that seen in the overall dataset.

Although the evaluation of participants' frying habits when preparing French fries in the controlled assay was restricted to decisions around frying end-point, such decisions were seen to have a great influence on the acrylamide content, moisture, weight loss and color of the French fries. Grob et al. (2003) described that acrylamide is extensively formed in the last moments of a frying of French fries (frozen material, $180 \circ \mathrm{C} / 6 \mathrm{~min}$ ) with a steep increase from about 80 to $320 \mu \mathrm{g} / \mathrm{kg}$. Considering the rate of acrylamide formation in our study for the time interval of $8.9 \mathrm{~s}(87.5-96.4 \mathrm{~s})$ and for the potato variety evaluated (Table 3), an increase in 120 $\mu \mathrm{g} / \mathrm{kg}$ acrylamide is calculated. Amrein et al. (2006) used a model of potato powder for studying the kinetics of acrylamide formation under controlled conditions (moisture, temperature, and time) by assuming a pseudo zero-order reaction. An increase up to $170 \mu \mathrm{g} / \mathrm{kg}$ of acrylamide for $8.9 \mathrm{~s}$ of heating at $167^{\circ} \mathrm{C}$ of a potato powder with $11.7 \mathrm{~g} / \mathrm{l} 00 \mathrm{~g}$ of moisture content was calculated with a rate of $19.0372 \mathrm{~s}^{-1}$. Palazoglu and Gökmen (2008) studied the kinetic of formation of acrylamide during frying of French fries at $170^{\circ} \mathrm{C}$ following an exponential modelling. In the range 4-5 min of frying time to get an acceptable final product for consumers, an increase of $8.9 \mathrm{~s}$ could represent approximatively an increase in $150 \mu \mathrm{g} / \mathrm{kg}$ in the final product.

Bivariate correlation analysis was applied to investigate the strength and direction of the relationships between the different parameters evaluated in the controlled assay and the acrylamide content (Table 4). In descending order with regards to the strength of associations, weight loss, color, frying time and moisture content all showed significant relationships with acrylamide content. Thus, there is a significant relationship between acrylamide content and participants' decisions to end the frying process. Indirectly, this decision would also influence the moisture, weight loss and color of the fried potato strip, since it is known that these variables are closely connected to acrylamide content under controlled conditions (Pedreschi et al., 2006; Medeiros et al., 2012; Yang et al., 2016; Rosen et al., 2018).

\subsection{Randomized assay}

Volunteers received the unhandled tubers (Elodie variety) and prepared French fries according to their usual culinary habits. The deepfryer used and the type of frying oil remained the same between participants (Fig. I). In the randomized assay, most volunteers peeled the potatoes $(96.3 \%)$ and removed the imperfections $(59.3 \%)$. Only four participants (14.8\%) washed the tubers before peeling, whereas $59.3 \%$ washed them after peeling, with $25.9 \%$ of these also drying (Table 2). Most of volunteers cut the potatoes into strips (88.9\%) and portion size distribution was seen to be homogeneous for $40.7 \%$ of the samples. Usually, the potato portions were not soaked $(88.9 \%)$ and, consequently, they were not drained or dried. Seven volunteers salted before frying (25.9\%), nine after frying (33.3\%) and the remaining did not add salt either before or after frying $(40.8 \%)$. The fries were cooked in a single frying cycle, except in two cases (7.4\%). These cases used a double-cycle, 
controlling the temperature in both. Most volunteers selected the frying end-point according to the overall appearance of French fries (92.6\%), with only two volunteers also taste testing them to check the texture.

The quantitative factors related to cooking practices (amount of potato, potato:oil ratio, frying time, initial and final temperature) were determined by participants' decisions and analysis (acrylamide, moisture, weight loss, color E-value) of the fried potato for the randomized assay (Table 3). The weight of potatoes intended for frying was somewhat variable between participants, ranging from 116 to $454 \mathrm{~g}$, and with randomized assay, oil was pre-tempered at $150 \circ \mathrm{C}$ and volunteers were free to change the temperature of the fryer at any time. Initial and final temperatures were $162.4 \pm 15.8 \circ \mathrm{C}$ and $149.9 \pm 9.9 \circ \mathrm{C}$, respectively. The total frying time varied greatly, with a mean of $235 \pm 107 \mathrm{~s}$. It is likely that frying time was conditioned by the potato to oil ratio used, with this ranging from 39 to $15 \mathrm{I}$, with a mean of $95.8 \pm 29.3$. When compared with the controlled assay, volunteers in the randomized assay used a significantly higher amount of potato and, consequently, a higher potato to oil ratio. Thus, participants in the randomized assay used significantly longer frying times than in the controlled assay (Table 4). There is a significant relationship between frying time and potato to oil ratio $(r=0.656, p<0.00 I)$, in addition to initial $(r=-0.525, p=0.010)$ and final temperature $(r=-0.622, p=$ 0.002). This relationship is in concordance with participants' decisions to extend frying time in order to achieve the fried potato characteristics preferred by participants at a high potato to oil ratio. Average acrylamide content for the fried potato in the randomized assay was $215 \pm 164 \mu \mathrm{g} / \mathrm{kg}$, with a minimum and maximum $95 \%$ confidence interval range of I50 and $280 \mu \mathrm{g} / \mathrm{kg}$, respectively. Mean moisture and weight loss were $67.9 \pm 3.8 \%$ and $35.6 \pm 10.9 \%$, respectively. When compared with the controlled assay, mean acrylamide and moisture content were significantly lower. However, weight loss was significantly higher in the randomized assay. Color differences between both assays were not significant, indicating that color criteria for determining when frying was finished were similar between both sets of participants. These results highlight that color preferences will drive participants' decisions relating to culinary practices during the cooking of French fries, regardless of frying conditions.

The bivariate correlations between acrylamide and the quantitative parameters were evaluated in the randomized assay (Table 4). Acrylamide was significantly correlated with moisture content in the fried potatoes $(\rho=-0.599, p=0.00 \mathrm{I})$. Extent of the dehydration of the fried potato is the consequence of the overall thermal input applied, furthermore inversely related to the formation of acrylamide. The chemistry of acrylamide formation is mainly driven by the intensity (temperature and time) of the thermal conditions applied, especially at temperatures higher than $175^{\circ} \mathrm{C}$ (Matthäus et al., 2004). The moisture content has a strong influence on the activation energy of acrylamide formation, that explains why the end of the frying process is critical (Amrein et al., 2006). The strength of this relationship was even more intense in the controlled assay without application of culinary practices that would affect the levels of the acrylamide precursors from the fresh tuber.

However, the relationships of acrylamide with the potato:oil ratio, frying time, temperature, weight loss and color were not significant $(p>0.05)$. This may be explained by the use of different culinary practices (Fig. I) by volunteers, leading to greater variability in the parameters evaluated. The influence of culinary practices on acrylamide content was further studied (Table 5). Participants were grouped according to whether they removed potato tuber defects (sprouts, black spots or freezing injury), washed the tuber before cutting, cut homogenous strips, washed the strips, soaked the strips, or salted. For this analysis, peeling and shape of the cut were not considered since all volunteers apart from one peeled the tuber and most cut the potato into strips ( $n=24)$ (Table 2). Different habits for defect removal, washing tubers, ensuring size homogeneity, soaking or salting did not significantly affect acrylamide formation in French fries (Table 5). However, 
acrylamide content was significantly lower when volunteers applied a soaking step to the potato strips. This culinary practice is, therefore, revealed to be relevant for reducing acrylamide precursor content in the fresh potato tuber in a randomized scenario. This is in line with EU recommendations around the regulation of acrylamide (EC, 2017). Reducing sugars are washed out from the external layer of the potato strips during soaking, then leads to leaching of acrylamide precursors (Grob et al., 2003; Matthäus et al., 2004; Pedreschi et al., 2006). In the present assay, 59.3\% of participants washed the strips (Table 2). For the potato variety evaluated, washing before frying had a significant effect on decreasing acrylamide content ( $156 \pm 76 \mu \mathrm{g} / \mathrm{kg})$ when compared with unwashed samples $(300 \pm 219 \mu \mathrm{g} / \mathrm{kg})(\mathrm{p}=0.022)$. In addition, French fries obtained from soaked potato strips displayed lower variability in acrylamide content than the group without soaking (Fig. 2). Soaking reduces uncertainty and risk associated with increasing acrylamide content when extended the frying time by a few seconds, as was highlighted in the controlled scenario. Soaking and blanching of potatoes were identified as factors for reduction of the risk associated to consumption of fried potato crisps for Irish consumers (Cummins et al., 2008). These results corroborate the effectiveness of soaking as a culinary practice for the mitigation of acrylamide formation in a domestic setting.

\subsection{Relationship with the benchmark level for acrylamide}

French fries contribute to chronic dietary acrylamide exposure in the population at all age ranges (EFSA, 20I5) and, for this reason, it is regulated by European Regulation (20I7)/2I58 (EC, 20I7). This regulation established a benchmark level of $500 \mu \mathrm{g} / \mathrm{kg}$ for acrylamide content in the category of "French fries (ready-to-eat)". The aim of this was to establish mitigation measures to reduce the presence of acrylamide in foods. Within this scope, it is necessary to identify whether consumer's practices when preparing French fries are adequate for maintaining below benchmark levels of acrylamide. In the controlled assay, $54 \%$ of the samples reported an acrylamide content lower than $500 \mu \mathrm{g} / \mathrm{kg}$, with an average of $300 \mu g / \mathrm{kg}(262-339 \mu \mathrm{g} / \mathrm{kg}, 95 \%$ C.I.). Further, $46 \%$ of the samples exceeded the benchmark level, with an average of $75 \mathrm{I} \mu \mathrm{g} / \mathrm{kg}(7 \mathrm{l} 0-793 \mu \mathrm{g} / \mathrm{kg}, 95 \%$ C.I.). In the randomized assay, 93\% of the samples had an acrylamide content lower than the benchmark level, with an average of $176 \mu \mathrm{g} / \mathrm{kg}$ ( $150-205 \mu \mathrm{g} / \mathrm{kg}, 95 \%$ C.I.), and only $7 \%$ of the samples reported an acrylamide content higher than $500 \mu \mathrm{g} / \mathrm{kg}$, with an average of $684 \mu \mathrm{g} / \mathrm{kg}(586-78 \mathrm{I} \mu \mathrm{g} / \mathrm{kg}, 95 \%$ C.I.). In both controlled and randomized assays, significant differences were observed between the two groups, with acrylamide contents that were both higher and lower than the benchmark value $(p<0.00 \mathrm{I})$ (Fig. 3). When comparing both trials, the randomized assay did not only show a higher percentage of samples with an acrylamide content below the benchmark level, but mean acrylamide content in the French fries $(214 \pm 164 \mu \mathrm{g} / \mathrm{kg})$ was also significantly lower than in the controlled assay $(508 \pm 302 \mu \mathrm{g} / \mathrm{kg})$ (Table 3).

The means and $95 \%$ confidence intervals of the frying time, moisture, weight loss and color-E were grouped according to the acrylamide benchmark level (<or $\geq 500 \mu \mathrm{g} / \mathrm{kg}$ ) (Table 6). Variables that previously showed a significant relationship with acrylamide content in the controlled assay (Table 4) were also robust enough to distinguish between the acrylamide benchmark level. Thus, $95 \%$ confidence intervals could be used to establish a safe threshold for frying practices in the observational controlled assay. In the potato variety evaluated in this study, the risk of obtaining French fries with an acrylamide content that is greater than the benchmark value increases when frying time is longer than $85 \mathrm{~s}$, weight loss is greater than $30.2 \%$, and moisture content in the fried potato is lower than $71.8 \%$. Since consumer's decisions around frying time also depend on the potato:oil ratio and temperature conditions, the weight loss variable will be used for further investigation. In the case of the randomized assay, many variables co-exist making it difficult to isolate a direct relationship. However, frying time was the only variable to produce significant differences with regards to the acrylamide benchmark level. The moisture content in the fried product was also strongly related, however, differences 
were not significant $(p=0.063)$ (Table 6). Considering confidence interval, frying times greater than $253 \mathrm{~s}$ might increase the risk of unsafe acrylamide levels. As previously discussed, a pre-frying culinary practice that may influence acrylamide content is the washing of potato strips. In this respect, in the randomized assay, the two samples with an acrylamide content higher than the benchmark level corresponded to participants who did not wash the strips prior to frying. Unfortunately, the impact of soaking cannot be evaluated since only II. I\% of participants completed this practice.

\subsection{Evaluation of acrylamide exposure from French fries}

Exposure to acrylamide from French fries was estimated using deterministic modelling by considering consumption frequency and portion size as reported in a questionnaire and the acrylamide content of the French fries prepared by each participant. Intake to this contaminant from French fries ranged between 0.00 and $61.45 \mu \mathrm{g} / \mathrm{day}$, with a mean value of $5.65 \mu \mathrm{g} / \mathrm{day}$. Assuming an average body weight (bw) of $70 \mathrm{~kg}$, mean daily acrylamide exposure of $0.08 \mu \mathrm{g} / \mathrm{kg}$ bw/day from French fries was estimated, ranging from 0.00 to 0.88 $\mu g / \mathrm{kg}$ bw/day. This estimation was similar to that observed for other countries in studies with different population groups such as one coming from Belgium (Claeys et al., 2016). It is lower than that reported for a youth population from Italy (Altissimi et al., 2017) and much lower than that observed in the general Danish population (Jakobsen et al., 2016).

Risk characterization for acrylamide in French fries was conducted, using MOE values of 125 and 10,000 as indicating no concern for neurotoxicity and carcinogenicity, respectively, in humans (EFSA, 2015). MOE was calculated as the BMDLI0 value divided by daily acrylamide exposure. As dictated by EFSA stipulations for acrylamide, $430 \mu \mathrm{g} / \mathrm{kg}$ bw/day was considered as the BMDLI0 value for neurotoxicity and $170 \mu \mathrm{g} / \mathrm{kg}$ bw/day as the value for carcinogenicity (EFSA, 20I5). In this respect, a mean MOE value of 5325 was obtained for neurotoxicity, reaching values of up to 490 for maximum exposure. Even this maximum value was above the safety limit of 125, which indicates no health concern (Supplementary Table 2). However, considering the BMDLIO for carcinogenicity, a mean value of 2105 was calculated, with an MOE of 194 for the volunteer with maximum exposure. In this case, eighty-one volunteers (63.8\%) exhibited MOE values below the safety limit of 10,000, suggesting a potential concern. Amongst participants with MOE values below 10,000, $44.5 \%$ reported consuming French fries several times a week, and $46.9 \%$ did so several times a month. There is an impact of the consumer's practices on the exposure for acrylamide in Fries in a domestic setting, therefore the risk evaluation for acrylamide could be more precisely refined. In addition, the limitations and uncertainties in the derivation of the MOE should be considered in any conclusion about the risk assessment. The calculated MOE arise from the dose-response data to determine the point of departure for risk assessment derived from rodent bioassays where differences in species toxicokinetics may have an impact on extrapolation to human exposure (Michael Bolger et al., 2010).

\section{CONCLUSIONS}

During the preparation of French fries, regardless of the potato:oil ratio and initial or final frying temperature, consumers freely chose when to stop frying in order to obtain a fried product which met their expectations regarding visual assessments of doneness. Under controlled conditions, consumers' decisions when setting the frying end-point significantly impacts on the moisture, weight loss, and acrylamide content of French fries. Within the framework of the potato variety selected for this study, mean acrylamide content was $508 \mu \mathrm{g} / \mathrm{kg}$ (448-568 $\mu \mathrm{g} / \mathrm{kg}$, C.I. 95\%), with $54 \%$ of samples showing an acrylamide content lower than the benchmark value set by EU Regulations (EC, 2017). It is noteworthy that the confidence interval (from 87.5 to $96.4 \mathrm{~s}$ ) for average frying time (91.9 s) had a range of only $8.9 \mathrm{~s}$. This could correspond to an increase of $120 \mu \mathrm{g} / \mathrm{kg}$ in the acrylamide content of the fried potato. Thus, the present observational study reinforces the importance of 
controlling frying time in order to maintain the acrylamide concentration of French fries prepared in a domestic setting below the benchmark level. In the randomized assay, many variables co-exist in a way that reflects the effect of consumers' practices during the preparation of French fries. Mean acrylamide content in the randomized assay was $215 \mu \mathrm{g} / \mathrm{kg}(\mathrm{I} 50-280 \mu \mathrm{g} / \mathrm{kg}, 95 \% \mathrm{Cl})$, with $93 \%$ of the samples reporting an acrylamide content lower than the benchmark value. In this scenario of high uncertainty, the moisture of the fried potato significantly correlates with acrylamide content, with frying time being the factor that most significantly determined whether acrylamide content was lower than the benchmark level. In addition, amongst the different culinary practices applied during the pre-frying stage in the randomized assay, washing of the potato strips significantly reduced the acrylamide content in the fried product. When taking together the frequency of consumption, portion size and acrylamide content, the estimated average dietary exposure to acrylamide from French fries in adults is $5.65 \mu \mathrm{g} /$ day. This corresponds to an MOE of 2105 for carcinogenicity. Results indicate that is necessary to promote educational initiatives aimed at the consumer to carry out a potato frying in a healthy way. In this sense, culinary practices such as washing and soaking, as well as controlling the frying time should be applied as mitigation strategies in the domestic environment to reduce the acrylamide levels during the preparation of French fries and, consequently, the potential risk associated with its exposure.

\section{CRediT authorship contribution statement}

Marta Mesias: Conceptualization, Methodology, Formal analysis, Investigation, Data curation, Writing - original draft, Writing - review \& editing, Visualization, Project administration, Funding acquisition. Cristina DelgadoAndrade: Conceptualization, Methodology, Validation, Investigation, Resources, Data curation, Writing original draft, Writing - review \& editing, Visualization, Project administration, Funding acquisition. Francisca Holgado: Formal analysis. Lucía González-Mulero: Formal analysis. Francisco J. Morales: Conceptualization, Methodology, Formal analysis, Software, Validation, Investigation, Resources, Data curation, Writing - original draft, Writing - review \& editing, Visualization, Supervision, Project administration.

\section{Declaration of competing interest}

The authors declare that they have no known competing financial interests or personal relationships that could have appeared to influence the work reported in this paper.

\section{Acknowledgements}

This research was partly funded by the Ministry of Economy and Competitiveness (Spain) under the projects SAFEFRYING (AGL 20I5-46234-R; MINECO/FEDER, UE), AVANSECAL-II-CM (S20I8/BAA-4393) and ACRINTAKE (RTI 2018-094402-B-100, MCIU/AEI/FEDER, UE). The authors thank the volunteers for their cooperation, and Ms. I. Alvarez and Ms. B. Díaz for their technical assistance.

\section{Appendix A. Supplementary data}

Supplementary data to this article can be found online at https://doi.org/10.1016/j.fct.2020.1 I I857.

\section{REFERENCES}

Abt, E., Robin, L.P., McGrath, S., Srinivasan, J., DiNovi, M., Adachi, Y., Chirtel, S., 2019. Acrylamide levels and dietary exposure from foods in the United States, an update based on 201 I-20I5 data. Food Addit. Contam. $1-16$.

Altissimi, M.S., Roila, R., Branciari, R., Miraglia, D., Ranucci, D., Framboas, M., Haouet, N., 20I7. Contribution of street food on dietary acrylamide exposure by youth aged nineteen to thirty in Perugia, Italy. Italian Journal of Food Safety 6, 688I. 
Amrein, T.M., Limacher, A., Conde-Petit, B., Amado, R., Escher, F., 2006. Influence of thermal processing conditions on acrylamide generation and browning in a potato model system. J. Agric. Food Chem. 54, 59I0 5916.

AOAC, 1999. Official Method of Analysis of AOAC Intl, sixteenth ed. Association of Official Analytical Chemists, Maryland.

Ayvaz, H., 2014. Rapid Assessment of Acrylamide and its Precursors in Potato Tubers and Snacks by Infrared Spectroscopy. PhD dissertation. Columbus, Ohio: Ohio State University.

Claeys, W., De Meulenaer, B., Huyghebaert, A., Scippo, M.L., Hoet, P., Matthys, C., 2016. Reassessment of the acrylamide risk: Belgium as a case-study. Food Contr. 59, 628-635.

Codex Alimentarius, 2009. Code of practice for the reduction of acrylamide in foods. CAC/RCP 67-2009. Available at: http://www.fao.org/fao-who-codexalimentarius/shproxy/en/?lnk=I \&url=https\%253A\%252F\%252Fworkspace.fao.org\%252Fsites\%252Fcodex\%252FStandards\%2 52FCXC\%2B67-2009\%252FCXP_067e.pdf.

Cummins, E., Butler, F., Gormley, R., Brunton, N., 2008. A methodology for evaluating the formation and human exposure to acrylamide through fried potato crisps. LWT - Food Sci. Technol. (LebensmittelWissenschaft -Technol.) 4I, 854-867.

De Wilde, T., De Meulenaer, B., Mestdagh, F., Govaert, Y., Ooghe, W., Fraselle, S., Demeulemeester, K., Van Peteghem, C., Calus, A., Degroodt, J.M., Verh'e, R., 2006. Selection criteria for potato tubers to minimize acrylamide formation during frying. J. Agric. Food Chem. 54, $2199-2205$.

EFSA (European Food Safety Authority), 2015. Scientific opinion on acrylamide in food. EFSA Journal I3 (6), 4104.

European Commission), E.C.(, 2017. Comission Regulation (EU) 2017/2I58 of 20 November 2017 establishing mitigation measures and benchmark levels for the reduction of the presence of acrylamide in food. Official Journal of the European Union L304, 24-44.

Farkas, T., Toulouee, J., 2003. Asparagine analysis in food products. LC-GC Eur. 21, I4-I6.

FDA, (Food and Drug Administration), 2016. Guidance for industry acrylamide in foods. https://www.fda.gov/media/87I50/download/. (Accessed 5 May 2020).

FDE (Food Drink Europe), 2019. The acrylamide toolbox. https://www.fooddrinkeurope. eu/uploads/publications_documents/FoodDrinkEurope_Acrylamide_Toolbox_2019.pdf/. (Accessed 9 May 2020).

Fiselier, K., Bazzocco, D., Gama-Baumgartner, F., Grob, K., 2006. Influence of the frying temperature on acrylamide formation in French fries. Eur. Food Res. Technol. 222, 4I4-4I9.

Friedman, M., 2015. Acrylamide: inhibition of formation in processed food and mitigation of toxicity in cells, animals, and humans. Food \& Function 6, 1752-1772.

FSA (Food Standards Agency), 2014. Acrylamide in the home: home-cooking practices and acrylamide formation. https://www.food.gov.uk/print/pdf/node/806/. (Accessed 5 May 2020).

Gökmen, V., Palazoglu, T.K., Senyuva, H.Z., 2006. Relation between the acrylamide formation and timetemperature history of surface and core regions of French fries. J. Food Eng. 77, 972-976. 
Gökmen, V., Senyuva, H.Z., Dülek, B., Çetin, A.E., 2007. Computer vision-based image analysis for the estimation of acrylamide concentrations of potato chips and French fries. Food Chem. 10I, 79I-798.

Grob, K., Biedermann, M., Biedermann-Brem, S., Noti, A., Imhof, D., Amrein, T., Bazzocco, D., 2003. French fries with less than $100 \mu \mathrm{g} / \mathrm{kg}$ acrylamide. A collaboration between cooks and analysts. Eur. Food Res. Technol. 217, 185-194.

Halford, N.G., Muttucumaru, N., Powers, S.J., Gillatt, P.N., Hartley, L., Elmore, J.S., Mottram, D.S., 2012. Concentrations of free amino acids and sugars in nine potato varieties: effects of storage and relationship with acrylamide formation. J. Agric. Food Chem. 60, 12044-12055.

IARC (International Agency for Research on Cancer) IARC, 1994. Some industrial chemicals. In: IARC Monographs on the Evaluation for Carcinogenic Risk of Chemicals to Humans, vol. 60. IARC, Lyon, France, Pp. 435-453.

Jakobsen, L.S., Granby, K., Knudsen, V.K., Nauta, M., Pires, S.M., Poulsen, M., 20I6. Burden of disease of dietary exposure to acrylamide in Denmark. Food Chem. Toxicol. 90, I5I-I59.

Joint FAO/WHO Expert Committee on Food Additives (JECFA), 20 I I. Evaluation of certain contaminants in food: seventy-second report of the joint FAO/WHO Expert committee on food Additives. Available online at: http://whqlibdoc.who.int/trs/WHO_TRS_959_eng.pdf.

Lineback, D.R., Coughlin, J.R., Stadler, R.H., 2012. Acrylamide in foods: a review of the science and future considerations. Annu Rev Food Sci Technol 3, I5-35.

Matthäus, B., Haase, N.U., Vosmann, K., 2004. Factors affecting the concentration of acrylamide during deepfat frying of potatoes. Eur. J. Lipid Sci. Technol. 106, 793-80I.

Medeiros Vinci, R., Mestdagh, F., Van Poucke, C., Kerkaert, B., de Muer, N., Denon, Q., Van Peteghem, C., De Meulenaer, B., 20II. Implementation of acrylamide mitigation strategies on industrial production of French fries: challenges and pitfalls. J. Agric. Food Chem. 59, 898-906.

Medeiros Vinci, R., Mestdagh, F., De Meulenaer, B., 2012. Acrylamide formation in fried potato products present and future, a critical review on mitigation strategies. Food Chem. 133, II38-1 I54.

Mesias, M., Morales, F.J., 20 I5. Acrylamide in commercial potato crisps from Spanish market: trends from 2004 to 2014 and assessment of the dietary exposure. Food Chem. Toxicol. 81, I04-II0.

Mesias, M., Delgado-Andrade, C., Holgado, F., Morales, F.J., 2018. Acrylamide content in French fries prepared in households: a pilot study in Spanish homes. Food Chem. 260, 44-52.

Mesias, M., Delgado-Andrade, C., Morales, F.J., 2019a. Alternative food matrices for snack formulations in terms of acrylamide formation and mitigation. J. Sci. Food Agric. 99, 2048-205I.

Mesias, M., Delgado-Andrade, C., Holgado, Morales, F.J., 2019b. Acrylamide content in French fries prepared in food service establishments. LWT Food Science and Technology 100, 83-91.

Mesias, M., Delgado-Andrade, C., Holgado, F., Morales, F.J., 2020. Impact of the consumer cooking practices on acrylamide formation during the preparation of French fries in Spanish households. Food Addit. Contam. 37, 254-266.

Michael Bolger, P., Leblanc, J.-C., Woodrow Setzer, R., 20I0. Application of the Margin of Exposure (MoE) approach to substances in food that are genotoxic and carcinogenic: example: Acrylamide (CAS No. 79-06I). Food Chem. Toxicol. 48, S25-S33.

M. Mesías et al. / Food and Chemical Toxicology 2021, 147, III857 pag. 14 
Miranda, M.L., Aguilera, J.M., 2006. Structure and texture properties of fried potato products. Food Rev. Int. 22, |73-20|.

Muttucumaru, N., Powers, S.J., Elmore, J.S., Dodson, A., Briddon, A., Mottram, D.S., Halford, N.G., 2017. Acrylamide-forming potential of potatoes grown at different locations, and the ratio of free asparagine to reducing sugars at which free asparagine becomes a limiting factor for acrylamide formation. Food Chem. 220, 76-86.

Palazoglu, T.K., G“okmen, V., 2008. Development and experimental validation of a frying model to estimate acrylamide levels in French fries. J. Food Sci. 73, El09-EII4.

Pedreschi, F., Kaack, K., Granby, K., 2006. Acrylamide content and color development in fried potato strips. Food Res. Int. 39, 40-46.

Powers, S.J., Mottram, D.S., Curtis, A., Halford, N.G., 2017. Acrylamide levels in potato crisps in Europe from 2002 to 2016. Food Addit. Contam. 34, 2085-2100.

Romani, S., Bacchiocca, M., Rocculi, P., Dalla Rosa, M., 2008. Effect of frying time on acrylamide content and quality aspects of French fries. Eur. Food Res. Technol. 226, 555-560.

Rosen, C., Sun, Na, Olsen, N., Thornton, M., Pavek, M., Knowles, L., Knowles, N.R., 2018. Impact of agronomic and storage practices on acrylamide in processed potatoes. Am. J. Potato Res. 96, 319-327.

Sanny, M., Jinap, S., Bakker, E.J., van Boekel, M.A.J.S., Luning, P.A., 2012. Possible causes of variation in acrylamide concentration in French fries prepared in food service establishments: an observational study. Food Chem. 132, 134-143.

Sanny, M., Luning, P.A., Jinap, S., Bakker, E.J., van Boekel, M.A.J.S., 20I3. Effect of frying instructions for food handlers on acrylamide concentration in French fries: an explorative study. J. Food Protect. 76, 462-472.

Stadler, R.H., Blank, I., Varga, N., Robert, F., Hau, J., Guy, P.A., Robert, M.C., Riediker, S., 2002. Acrylamide from Maillard reaction products. Nature 419, 449-450.

Storey, M., 2007. The harvested crop. In: Vreugdenhil, D. (Ed.), Potato Biology and Biotechnology Advances and Perspectives. Elsevier, Oxford, pp. 44I-470.

Vivanti, V., Finotti, E., Friedman, M., 2006. Level of acrylamide precursors asparagine, fructose, glucose, and sucrose in potatoes sold at retail in Italy and in the United States. J. Food Sci. 7, C8I-C85.

Yang, Y., Achaerandio, I., Pujol 'a, M., 2016. Influence of the frying process and potato cultivar on acrylamide formation in French fries. Food Contr. 62, 216-223.

Yuan, Y., Zhao, G., Chen, F., Liu, J., Wu, J., Hu, X., 2008. Correlation of methylglyoxal with acrylamide formation in fructose/asparagine Maillard reaction model system. Food Chem. 108, 885-990.

Zamora, R., Hidalgo, F.J., 2008. Contribution of lipid oxidation products to acrylamide formation in model systems. J. Agric. Food Chem. 58, 6075-6080. 
Table I. Description of the number $(n)$ and percentage of cases $(\%)$ in the controlled assay $(n=100)$, randomized assay $(n=27)$, and the combined dataset of both assays $(n=127)$ for several descriptors related to gender, age group (years), and habits for the preparation and consumption (frequency and portion size in grams) of French fries.

\begin{tabular}{|c|c|c|c|}
\hline & $\begin{array}{c}\text { Controlled } \\
\text { assay } \\
(\mathrm{n}, \%)\end{array}$ & $\begin{array}{c}\text { Randomized } \\
\text { assay } \\
(\mathrm{n}, \%)\end{array}$ & $\begin{array}{c}\text { Combined } \\
\text { dataset } \\
(n, \%)\end{array}$ \\
\hline \multicolumn{4}{|l|}{ Gender } \\
\hline Female & $74(74.0)$ & $17(63.0)$ & 91 (7I.7) \\
\hline Male & $26(26.0)$ & $10(37.0)$ & $36(28.3)$ \\
\hline \multicolumn{4}{|l|}{ Age group } \\
\hline $18-30 y$ & $34(34.0)$ & $5(18.5)$ & $39(30.7)$ \\
\hline $31-45 y$ & $28(28.0)$ & $5(18.5)$ & $33(26.0)$ \\
\hline $46-65 y$ & $37(37.0)$ & $17(63.0)$ & $54(42.5)$ \\
\hline$>65 y$ & $\mathrm{I}(\mathrm{I} .0)$ & $0(0.0)$ & $\mathrm{I}(0.8)$ \\
\hline \multicolumn{4}{|l|}{ Cooking experience } \\
\hline Expert & $4(4.0)$ & $0(0.0)$ & $4(3.1)$ \\
\hline High & $46(46.0)$ & $16(59.2)$ & $62(48.8)$ \\
\hline Medium & $34(34.0)$ & $8(29.7)$ & $42(33.1)$ \\
\hline Basic & $14(14.0)$ & $3(11.1)$ & $17(13.4)$ \\
\hline None & $2(2.0)$ & $0(0.0)$ & $2(1.6)$ \\
\hline \multicolumn{4}{|l|}{ Consumption frequency } \\
\hline Weekly (several times a week) & $29(29.0)$ & $7(25.9)$ & $36(28.3)$ \\
\hline Monthly (several times a month) & $37(37.0)$ & $13(48.2)$ & $50(39.4)$ \\
\hline Occasionally & $27(27.0)$ & $7(25.9)$ & $34(26.8)$ \\
\hline Never & $7(7.0)$ & $0(0.0)$ & $7(5.5)$ \\
\hline \multicolumn{4}{|l|}{ Portion size (g) } \\
\hline 20 & I (I.0) & $0(0.0)$ & $\mathrm{I}(0.8)$ \\
\hline 40 & $22(22.0)$ & $4(14.9)$ & $26(20.5)$ \\
\hline 55 & $20(20.0)$ & 7 (25.9) & $27(2 \mid .3)$ \\
\hline 70 & $4 \mid(4 \mid .0)$ & $7(25.9)$ & $48(37.8)$ \\
\hline 85 & $4(4.0)$ & $3(11.1)$ & $7(5.5)$ \\
\hline 100 & $9(9.0)$ & $3(11.1)$ & $12(9.4)$ \\
\hline 130 & $3(3.0)$ & $3(11.1)$ & $6(4.7)$ \\
\hline
\end{tabular}


Table 2. Description of practices used for the preparation of French fries in the different assays, expressed as number of cases $(n)$ and percentage.

\begin{tabular}{|c|c|c|c|c|c|c|}
\hline & \multicolumn{3}{|c|}{ Controlled assay } & \multicolumn{3}{|c|}{ Randomized assay } \\
\hline & $(\mathrm{n}, \%)$ & $(\mathrm{n}, \%)$ & $(\mathrm{n}, \%)$ & $(n, \%)$ & $(n, \%)$ & $(n, \%)$ \\
\hline \multicolumn{7}{|l|}{ Pre-frying stage } \\
\hline & yes & no & & yes & no & \\
\hline Peeling & $100(100.0)$ & $0(0.0)$ & & $26(96.3)$ & I (3.7) & \\
\hline Defect removal & $100(100.0)$ & $0(0.0)$ & & $16(59.3)$ & II (40.7) & \\
\hline Wash tuber & $0(0.0)$ & $100(100.0)$ & & $4(14.8)$ & $23(85.2)$ & \\
\hline Dried after washing & $0(0.0)$ & $100(100.0)$ & & $7(25.9)$ & $20(74.1)$ & \\
\hline Size homogeneity & $100(100.0)$ & $0(0.0)$ & & II (40.7) & $16(59.3)$ & \\
\hline Wash strips & $0(0.0)$ & $100(100.0)$ & & $16(59.3)$ & II (40.7) & \\
\hline Soaking & $0(0.0)$ & $100(100.0)$ & & $3(11.1)$ & $24(88.9)$ & \\
\hline Draining & $0(0.0)$ & $100(100.0)$ & & $2(7.4)$ & $25(92.6)$ & \\
\hline Drying after soaking & $0(0.0)$ & $100(100.0)$ & & $3(11.1)$ & $24(88.9)$ & \\
\hline \multirow[t]{2}{*}{ Salt before frying } & $0(0.0)$ & $100(100.0)$ & & $7(25.9)$ & $20(74.1)$ & \\
\hline & strips & cubes & slices & strips & cubes & slices \\
\hline Type of cut & $100(100.0)$ & $0(0.0)$ & $0(0.0)$ & $24(88.9)$ & $2(7.4)$ & I (3.7) \\
\hline \multicolumn{7}{|l|}{ Frying stage } \\
\hline & yes & no & & yes & no & \\
\hline \multirow[t]{2}{*}{ Temperature control } & $100(100.0)$ & $0(0.0)$ & & $100(100.0)$ & $0(0.0)$ & \\
\hline & one & two & & one & two & \\
\hline \multirow[t]{2}{*}{ Frying cycles } & $100(100.0)$ & $0(0.0)$ & & $25(92.6)$ & $2(7.4)$ & \\
\hline & color & texture & & color & texture & \\
\hline End-point criteria & $100(100.0)$ & $0(0.0)$ & & $25(92.6)$ & $2(7.4)$ & \\
\hline \multicolumn{7}{|l|}{ Post-frying stage } \\
\hline & yes & no & & yes & no & \\
\hline Remove excess oil & $100(100.0)$ & $0(0.0)$ & & missing & missing & \\
\hline Salt after frying & $0(0.0)$ & $100(100.0)$ & & $9(33.3)$ & $18(66.7)$ & \\
\hline
\end{tabular}


Table 3. Statistical description of the factors accounting for frying practices (amount of potato strips in the fryer-basket, potato:oil ratio in the fryer, total frying time, initial and final frying temperatures) and analysis of French fries (acrylamide, moisture content, weight loss, and color) in the controlled $(n=100)$ and randomized assays $(n=27)$. SD (standard deviation), 95\% confidence interval $(\mathrm{Cl})$. *Asterisk indicates significant differences $(p<0.05)$.

\begin{tabular}{|c|c|c|c|c|c|c|c|c|c|c|}
\hline \multirow{2}{*}{$\begin{array}{l}a \\
a\end{array}$} & \multicolumn{4}{|c|}{ Controlled Assaya } & \multicolumn{2}{|r|}{$a$} & \multicolumn{3}{|c|}{ Randomized·Assaya } & \multirow{2}{*}{$\frac{p \text {-valuea }}{x}$} \\
\hline & Mediana & Meana & SDa & (Min.-Max.,'CI) $\mathfrak{a}$ & a & Mediana & Meana & SDa & (Min.-Max., $\cdot$ CI) $\mathfrak{a}$ & \\
\hline Processing $a$ & $a$ & $a$ & $a$ & $a$ & $a$ & a & $a$ & $a$ & $a$ & $a$ \\
\hline Potato'strips $(\mathrm{g}) \mathrm{g}$ & 43.00 & $43.4 \alpha$ & $2.7 \propto$ & $(42.8 \cdot-43.9) \propto$ & $a$ & $291.0 \propto$ & $287.4 \not$ & $88.0 \mathrm{a}$ & $(252.6 \cdot-322.2)^{d}$ & $<\cdot 0.0001 \cdot * a$ \\
\hline Potate:oil ratioca & 14.30 & 14.5 무 & 0.90 & $(14.3 \cdot-15.6) a$ & $a$ & 97.0 a & $95.8 a$ & $29.3 a$ & $(84.2 \cdot-107.4) \propto$ & $<\cdot 0.0001 \cdot * a$ \\
\hline Frying time $\cdot(\mathrm{s}) \mathrm{d}$ & 89.00 & $91.9 \mathrm{a}$ & 22.60 & $(87.5 \cdot-96.4)^{\mathfrak{d}}$ & a & 220.00 & $235.3 a$ & $107.4 \mathrm{a}$ & $(192.8 \cdot-277.7) \mathrm{d}$ & $<0.0001 \cdot * 0$ \\
\hline Initial temperature $\left({ }^{\circ} \mathrm{C}\right)^{\alpha} \alpha$ & $175.0 \mathrm{a}$ & $175.0 \mathrm{a}$ & a & a & $a$ & $162.2 \alpha$ & $162.4 \mathrm{a}$ & $15.8 \mathrm{a}$ & $(155.5 \cdot-169.2)^{\mathfrak{d}}$ & $a$ \\
\hline Final temperature $\cdot\left({ }^{\circ} \mathrm{C}\right) \propto$ & $168.5 a$ & $167.7 \propto$ & 3.40 & $(167.1 \cdot-168.4) d$ & $a$ & $152.3 \mathrm{a}$ & $149.9 a$ & 9.90 & $(145.6 \cdot-154.2) \mathrm{d}$ & $<\cdot 0.0001 \cdot * a$ \\
\hline Fried $\cdot$ Potato & a & $a$ & a & a & $a$ & a & $a$ & $a$ & $a$ & a \\
\hline Acrylamide $(\mu \mathrm{g} / \mathrm{kg})$ ca & 460 & 508 & $302 \propto$ & $(448--568) \propto$ & $a$ & 1800 & $215 a$ & $164 \propto$ & $(150-280) a$ & $<0.0001 \cdot * a$ \\
\hline Moisture $(\%) \mathfrak{a}$ & 71.20 & $71.0 \propto$ & 2.30 & $(70.6 \cdot-71.5) \propto$ & a & 68.40 & 67.90 & $3.8 a$ & $(66.4 \cdot-69.5)^{\mathrm{a}}$ & $<0.0001 \cdot *$ \\
\hline Weight $\cdot$ loss $\cdot(\%)$ a & $31.4 \mathrm{~d}$ & $31.3 \alpha$ & $2.7 \propto$ & $(30.8 \cdot-32.9)^{\mathfrak{d}}$ & a & 32.80 & 35.60 & $10.9 \mathrm{a}$ & $(31.3 \cdot-39.9) \mathrm{d}$ & $0.0004 \cdot * a$ \\
\hline CIELab:(E-value)a & $61.0 \mathrm{da}$ & 60.80 & 2.60 & $(60.3 \cdot-\cdot 61.3) \propto$ & $a$ & 60.30 & 59.9 a & $2.9 x$ & $(58.8 \cdot-61.1)^{a}$ & 0.15010 \\
\hline
\end{tabular}


Table 4. Bivariate correlations (Spearman coefficient correlation, $\rho$ ) between acrylamide $(\mu g / \mathrm{kg})$ and other quantitative descriptors of the domestic preparation of French fries in the controlled $(n=100)$ and randomized assays $(n=27)$.

\begin{tabular}{rllll}
\hline & \multicolumn{2}{l}{ Controlled Assay } & \multicolumn{2}{l}{ Randomized Assay } \\
\hline Potato:oil ratio & $0.15 \mathrm{I}$ & 0.133 & 0.292 & 0.140 \\
Frying time & -0.698 & $0.000 * * *$ & 0.293 & 0.138 \\
End temperature & 0.008 & 0.937 & 0.314 & 0.144 \\
Moisture & -0.546 & $0.000 * * *$ & -0.599 & $0.001 * *$ \\
Weight loss & 0.754 & $0.000 * * *$ & 0.321 & 0.102 \\
CIELab* E-value & 0.703 & $0.000 * * *$ & 0.005 & 0.978 \\
\hline * & & & & \\
\hline
\end{tabular}


Table 5. Acrylamide content in French fries ( $\mu \mathrm{g} / \mathrm{kg}$ fresh weight), grouped according to the application (Yes) or not (NO) of different culinary practices before frying in the randomized assay $(n=27)$.

\begin{tabular}{|c|c|c|c|c|c|}
\hline & \multicolumn{2}{|c|}{ Yes } & \multicolumn{2}{|c|}{ No } & \multirow[b]{2}{*}{$p$-value } \\
\hline & Mean & SD & Mean & SD & \\
\hline Defect removal & 216 & $|7|$ & 213 & $\mid 161$ & 0.956 \\
\hline Washing tuber & 373 & 229 & 187 & 139 & 0.205 \\
\hline Size homogeneity & 201 & 176 & 224 & 161 & 0.736 \\
\hline Washing strips & 156 & 76 & 300 & 219 & $0.022 *$ \\
\hline Soaking & 183 & 92 & 219 & 172 & 0.599 \\
\hline Salting & 156 & 95 & 236 & 180 & 0.154 \\
\hline
\end{tabular}

*Asterisk indicates significant differences $(\mathrm{p}<0.05)$ 
Table 6. Table of means and $95 \%$ confidence intervals for the group of samples with acrylamide content lower and greater than the benchmark level established by the European Regulation 2017/2/58 for the controlled and randomized assay, and different descriptors for the preparation of French fries.

\begin{tabular}{|c|c|c|c|c|c|c|c|}
\hline \multirow{2}{*}{$\begin{array}{l}\alpha \\
a\end{array}$} & \multicolumn{3}{|c|}{ Controlled'assaya } & 90 & \multicolumn{3}{|c|}{ Randomized·assaya } \\
\hline & Benchma & ark'levela & $a$ & $a$ & Benchma & ark'levela & $a$ \\
\hline 90 & $<\cdot 500 \cdot \mu \mathrm{g} / \mathrm{kga}$ & $\geq \cdot 500 \cdot \mu \mathrm{g} / \mathrm{kga}$ & $p$-value $\alpha$ & a & $<\cdot 500 \cdot \mu \mathrm{g} / \mathrm{kga}$ & $\geq 500 \cdot \mu \mathrm{g} / \mathrm{kga}$ & p-value \\
\hline Frying time $(\mathrm{s}) \mathrm{a}$ & $81 \cdot(77 \cdot-85) a$ & $105 \cdot(101 \cdot-109) a$ & $<-0.00010$ & $=0$ & $224 \cdot(194 \cdot-253) a$ & $378 \cdot(273 \cdot-482)^{a}$ & 0.04940 \\
\hline Moisture $(\%) \propto$ & $72.2 \cdot(71.8 \cdot-72.6)^{\mathrm{d}}$ & $69.7 \cdot(69.3 \cdot-70.1)^{\mathrm{d}}$ & $<-0.00010$ & 0 & $68.3 \cdot(67.3 \cdot-69.4) \mathrm{d}$ & $63.1 \cdot(59.4 \cdot-66.9) \alpha$ & 0.0633 \\
\hline Weight-loss $\cdot(\%) a$ & $29.8 \cdot(29.4 \cdot-\cdot 30.2)^{\mathfrak{a}}$ & $33.1 \cdot(32.7 \cdot-33.5) \mathfrak{a}$ & $<-0.00010$ & $=a$ & $35.1 \cdot(32.0 \cdot-38.3) \propto$ & $41.8 \cdot(30.5 \cdot-53.0) a$ & 0.41760 \\
\hline CIELab-Eם & $62.0 \cdot(61.6 \cdot-52.5) \mathrm{d}$ & $59.3 \cdot(58.8 \cdot-59.7) \mathrm{d}$ & $<-0.00010$ & & $60.1 \cdot(59.3 \cdot-61.0) d$ & $57.7 \cdot(54.7 \cdot-60.6)^{\mathrm{d}}$ & 0.2581 \\
\hline
\end{tabular}


Figure I. Description of the practices employed during the culinary preparation of French fries by volunteers in the controlled and randomized assays. Practices are grouped into pre-frying, frying and post-frying stages. The list does intend to follow a sequential order of action since this varied according to volunteers habits, instead simply recording the practices observed. Superscripts indicate fixed practices in the controlled assay (*) and in the randomized assay (\#).

\begin{tabular}{|c|}
\hline Pre-frying stage \\
\hline \hline Potato variety *\# \\
Soil removal * \\
Peeling * \\
Defect removal * \\
Washing tuber \\
Drying \\
Cutting * \\
Washing strips \\
Soaking \\
Draining \\
Salting \\
\hline
\end{tabular}

\begin{tabular}{|c|}
\hline \\
\hline \\
\hline \\
Frying stage \\
Temperature *\# \\
Frying oil *\# \\
Potato:oil ratio * \\
End-time \\
Inspection/taste \\
Num. cycles *
\end{tabular}

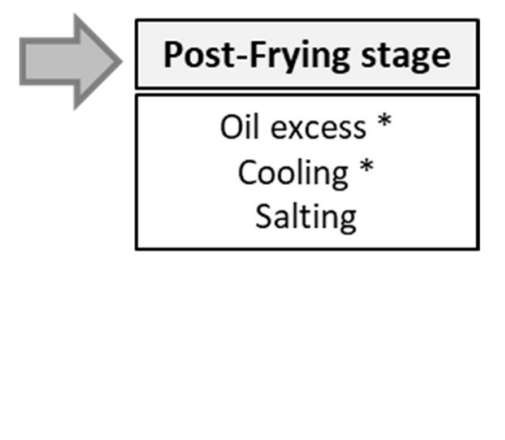


Figure 2. Effect of washing potato strips before frying on acrylamide content $(\mu \mathrm{g} / \mathrm{kg})$ in the randomized assay. * Asterisk indicates significant difference between samples $(p<0.05)$.

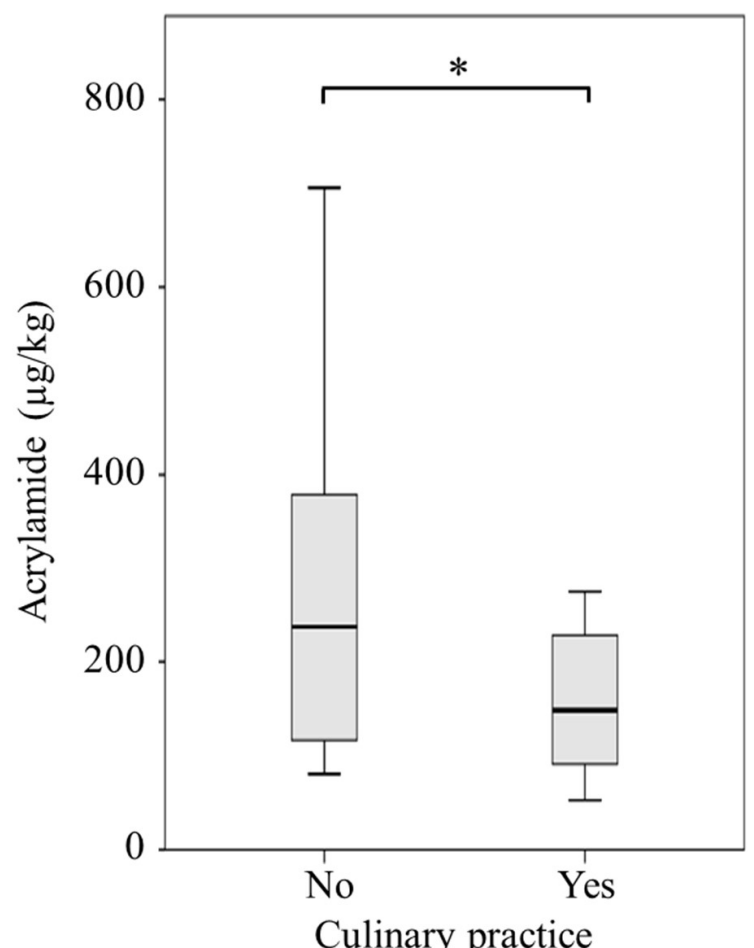

(washing potato strips before frying) 
Figure 3. Distribution of samples above (dark bar, $\geq 500 \mu \mathrm{g} / \mathrm{kg}$ ) or below (grey bar, $<500 \mu g / \mathrm{kg}$ ) the benchmark level for acrylamide in French fries based on European Regulation 2017/2I58 (500 $\mu \mathrm{g} / \mathrm{kg})$ in the controlled and randomized assays. ${ }^{*}$ asterisk indicates significant difference between samples ( $p$-value $\left.<0.05\right)$.

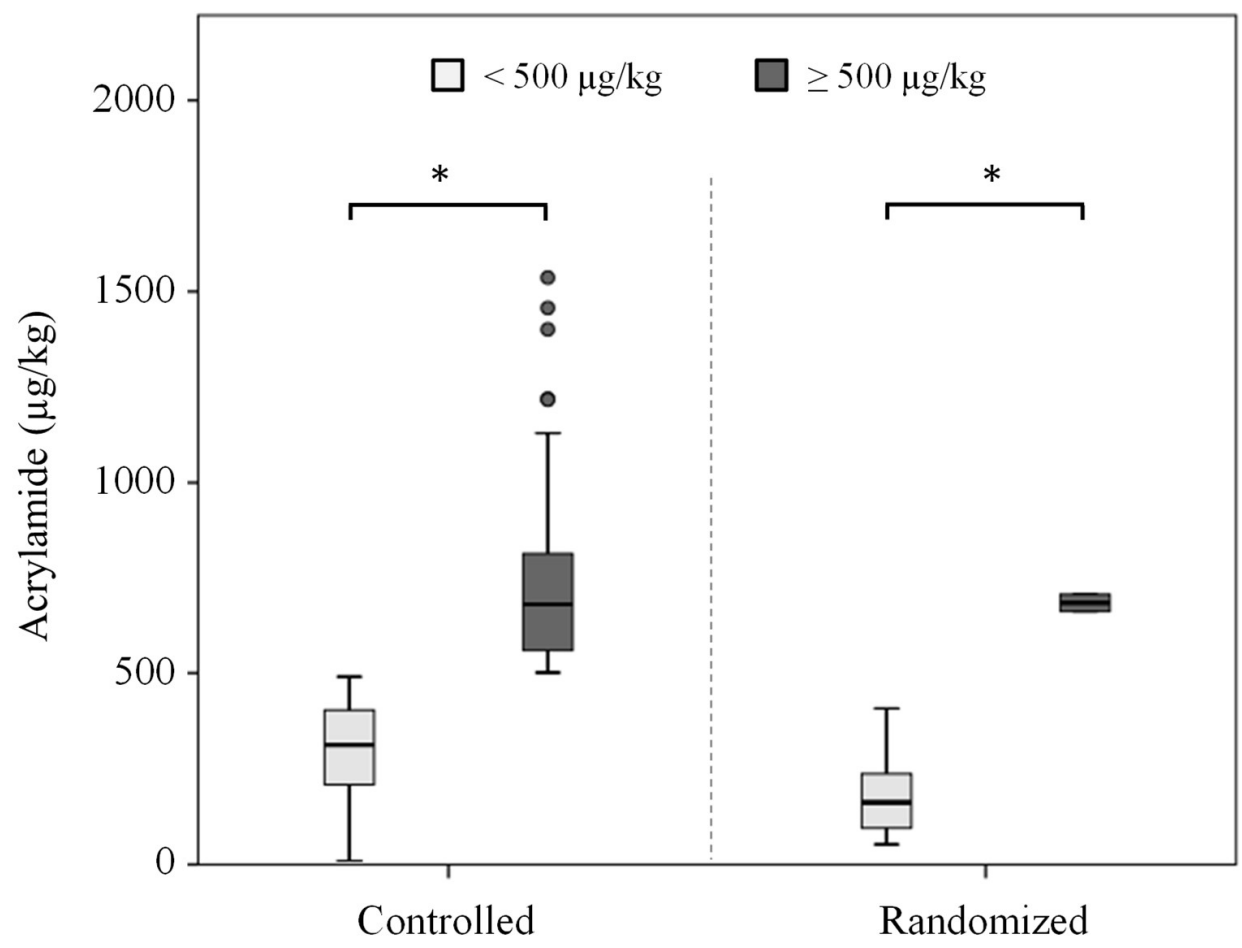

Observational assays 